JAUR, Vol. 3 (2) April (2020) ISSN: 2599-0179 (Print) ISSN: 2599-0160 (Online) 10.31289/jaur.v3i2.3344

JOURNAL OF ARCHITECUTRE AND URBANISM RESEARCH

Available online http://ojs.uma.ac.id/index.php/jaur

\title{
Strategi Potensi Dalam Pengembangan Wisata Ice Skating Di Dalam Mall Jakarta (Studi Kasus: Sky Rink Taman Anggrek Jakarta)
}

\section{Potential Strategy In Development Of Ice Skating Tourism In Jakarta Mall (Case Study: Sky Rink Taman Anggrek Jakarta)}

\author{
${ }^{*}$ Annica Etenia ${ }^{1)}$, R. Siti Rukayah ${ }^{2)}$ \& Wijayanti ${ }^{3) *}$
}

1) Mahasiswa Pascasarjana Departemen Arsitektur, Fakultas Teknik, Universitas Diponegoro

2) Departemen Arsitektur, Fakultas Teknik, Universitas Diponegoro

3) Departemen Arsitektur, Fakultas Teknik, Universitas Diponegoro

Diterima: Februari 2020; Disetujui: April 2020; Dipublikasi: 30 April 2020

*Corresponding author: E-mail :annicaetenia94@gmail.com

\begin{abstract}
Abstrak
Ice skating is a winter sport that is rarely in demand by Indonesians mainly because of the tropical climate, and the lack of knowledge about the sport around the community. This phenomenon has aroused the public's curiosity in winter sports. Therefore several malls in Jakarta have implemented ice skating tours in recreational entertainment facilities provided to attract the attention of visitors, one of which is Sky Rink in Mall Taman Anggrek. The trend is an exciting thing to study as potential in the concept of ice sports tourism in the mall. In this study explains the possibilities of this ice tourism. The method used is a qualitative SWOT approach by explaining the potential, weaknesses, opportunities and threats while the results of the study are descriptive explanations of the potential in developing ice skating tours in the mall.
\end{abstract}

Kata Kunci: ice skating, mall, wisata, ice rink

\begin{abstract}
Ice skating merupakan olahraga musim dingin yang jarang diminati oleh orang Indonesia terlebih karena iklim yang tropis, serta kurang tahunya masyarakat sekitar tentang olahraga ini. Fenomena ini menimbulkan penasaran masyarakat dalam olahraga musim dingin tersebut, oleh sebab itu beberapa mall di Jakarta telah menerapkan wisata ice skating dalam fasilitas hiburan rekreasi yang disediakan untuk menarik perhatian pengunjung, salah satunya Sky Rink yang ada di Mall Taman Anggrek. Trend tersebut menjadi hal yang menarik untuk dikaji sebagai potensi dalam konsep wisata olahraga es di dalam mall. Dalam penelitian ini menjelaskan mengenai potensi-potensi tentang wisata es ini. Metode yang digunakan yaitu dengan pendekatan SWOT kualitatif dengan memberikan penjelasan mengenai potensi, kelemahan, kesempatan dan ancaman. Sedangkan hasil dari penelitian berupa penjelasan deskrptif mengenai potensi dalam mengembangkan wisata ice skating di dalam mall.

Keywords: ice skating, malls, sport tourism, ice rinks
\end{abstract}

How to Cite : E. Annica, R.Stiti R, Wijayanti, (2020), Strategi Potensi dalam Pengembangan Wisata Ice Skating di dalam Mall Jakarta (studi Kasus Sky Rink Taman Anggrek Jakarta), Journal of Architecture and Urbanism Research, 3 (2): Hal 95-103. 


\section{PENDAHULUAN}

Kehidupan kota yang ramai dan padat ini, masyarakat Jakarta serta penduduk yang bertambah menyebabkan gaya hidup masyarakat Jakarta yang sangat tinggi, sehingga masyarakat Jakarta menghabiskan waktu bersama keluarga di mall. Di Jakarta sendiri jumlah bangunan pusat perbelanjaan atau mall mencapai 564 mall yang tersebar di seluruh area. Rinciannya 132 dikategorikan sebagai mall, sedangkan sisanya swalayan, pusat grosir, pertokoan, dan pasar tradisional (data.jakarta.go.id). Di sisi lain, persaingan mall juga terjadi, hingga meningkatkan kualitas dan penambahan area wisata yang sangat bervariasi untuk meningkatkan pengunjung mall. Banyak mall di Jakarta yang sepi pengunjung, retailretail terlihat kosong, tidak dapat beroperasi dengan baik, bahkan pada interiornya sudah tidak laik huni dan beton-betonnya berkarat.

Salah satu mall di Jakarta yang memperhatikan fasilitas tersebut adalah Mall Taman Anggrek, dibuka pada tahun 1996, merupakan pusat perbelanjaan terbesar di Asia Tenggara. Pada fasad bangunan mall terdapat LED terbesar di dunia. Bangunan mal ini terdiri dari 8 menara yang bisa menampung lebih dari 500 toko yang tersebar dalam 7 lantai. Pada mall tersebut terdapat wahana gelanggang es di dalam ruangan yang menjadi mall pertama di Indonesia. Tahun 2013, anakanak hingga remaja mengikuti kegitan ice skating yang sudah disiapkan di Sky Rink, Mall Taman Anggrek Jakarta. Sky Rink merupakan salah satu salah satu wahana seluncur es indoor terluas, fasilitas yang dimiliki yaitu ice rink dengan area luasan $1.248 \mathrm{~m} 2$, yang merupakan salah satu gelangganv es indoor terluas di Indonesia.

Supaya diminati pengunjung mall, Sky Rink selalu mengevaluasi dan menciptakan inovasi baru yang dapat membuat para pengunjung merasa senang. Inovasi yang disediakan yaitu berupa layanan bermain ice skating sepuasnya pada hari kerja, pelayanan meminjamkan sepatu skating gratis, serta adanya diskon di harihari tertentu, (Great Monday, Bonanza Day, Karyawan Day, dan Campus Day), Sky Rink juga menyajika pertunjukan yang mampu meningkatkan pengunjung mall yaitu kompetisi ice skating baik tingkat lokal maupun tingkat internasional (Aulia Novita, 2010).

Sky rink ini selalu ramai pengunjung setiap harinya dan tidak pernah sepi. Sehubungan dengan uraian diatas maka penulis tertarik untuk mengetahui lebih jauh tentang sky rink serta memberikan suatu konsep desain ruangan yang baik dengan tujuan untuk menambah daya tarik minat sky rink. Penelitian ini bertujuan untuk mengetahui Potensi wisata ice skating di dalam mall Taman Anggrek Jakarta.

Adapun Rumusan masalah yang dibahas dalam penelitian ini adalah : (a) mengetahui potensi - potensi ice skating terhadap minatnya warga kota Jakarta, (b) mengetahui potensi berdasarkan analisa SWOT yang bisa menarik ketertarikan pengunjung ke Mall Taman Anggrek terhadap ice skating.

Menurut (Rubenstein, 1978) Mall didefinisikan sebagai sebuah wilayah kegiatan bergerak atau lintasan yang memutar pada suatu area komersial atau bisnis (central city business area) biasanya diisi oleh pejalan kaki tidak ada kendaraan di area tersebut, pada visual ruang berbentuk pedestrian luas dengan kombinasi retail, pertokoan dan area pertemuan. Menurut (Lion, 1976) jenis pusat perbelanjaan bisa dikelompokkan menjadi dua bentuk yaitu strip center dan mall. Strip center merupakan suatu area perbelanjaan dengan retail-retail yang berdampingan dan 
menyatu dan membentuk gabu ngan dari aktivitas perdagangan eceran, pada tampak visual toko biasanya menggunakan kanopi.

Menurut tinjauan pustaka mall merupakan area tertutup difasilitasi pendingin ruangan, memiliki koridor yang luas dikelilingi oleh toko yang saling berhadapan, biasanya bentuk mall ini direncanakan dengan standar yang sesuai dengan jenis tipe standar regional center atau super regional center (Sari, 2017).

Berdasarkan Norval dalam Muljadi dan (Nurhayati, 2013) pariwisata merupakan suatu kegiatan yang mencakup dari alur masuk, menetap, serta meninggalkan tempat tertentu di suatu negara, kota, atau daerah tertentu. Sedangkan pengertian secara luas oleh (Kodhyat, 1983) pariwisata merupakan kunjungan ke suatu area lain ke area lainnya yang bersifat temporer baik satu orang maupun perkumpulan dengan tujuan mencari suasana bahagia dengan lingkungan yang ada di daerahnya dalam segi aspek keanekaragaman sosial, budaya, dan pengetahuan.

Berdasarkan (Yoeti, 2008) pariwisata memiliki beberapa kriteria yang harus dipenuhi, yaitu: (a) Perjalanan biasanya berpindah - pindah dari suatu tempat ke tempat lainnya dari orang itu menetap. (b) Target dari perjalanan tersebut hanya untuk senang tanpa memikirkan kegiatan lainnya yang mempengaruhi wisatawan tersebut dalam perjalanan. (c) Dana yang digunakannya berasal dari negara asalnya, bukan uang yang ia dapatkan dari hasil dari kegiatan perjalanan yang dilakukannya, (d) Perjalanan biasanya bisa dilakukan dalam 24 jam ataupun berhari-hari

Dari beberapa pengertian diatas dapat disimpulkan pariwisata merupakan kegiatan perjalanan wisatawan mengunjungi tempat lain yang bersifat sementara tidak menetap, dengan tujuan hanya untuk menikmati daerah tersebut hanya sebagai seorang wisatawan.

Dalam teori pariwisata olahraga, biasanya pengunjung ke area wisata ikut serta dalam olahraga (Wardana \& Sanawiri, 2018), sedangkan menurut (De Knop, 1999) pariwisata olahraga pengunjung sebagai keterlibatan dapat berpartisipasi secara santai atau di jalur terorganisir untuk alasan non-komersial atau bisnis / komersial yang mengharuskan perjalanan jauh dari rumah dan tempat bekerja. Selain itu, (Pitts, 1999) percaya bahwa dari perspektif pemasaran dan manajemen olahraga, pariwisata olahraga terdiri dari dua kategori produk yang luas: perjalanan partisipasi olahraga (perjalanan untuk tujuan berpartisipasi dalam kegiatan olahraga, rekreasi, rekreasi, atau kebugaran); Perjalanan spektator olahraga (perjalanan untuk tujuan menyaksikan kegiatan, acara olahraga, rekreasi, rekreasi atau kebugaran).

Dengan kata lain, pengunjung wisata olahraga dapat dimotivasi terutama oleh olahraga atau perjalanan selama berwisata di wisata olahraga, dan merupakan menjadi sebuah pemacu untuk bersemangat dalam olahraga baik untuk olahragawan pasif maupun aktif.

\section{METODE PENELITIAN}

Dengan Adapun metode yang digunakan adalah dengan menggunakan penggalian data melalui observasi dengan mengamati langsung lokasi penelitian agar mengetahui potensi - potensi yang ada di area Ice Skating, tingkat aksesibilitas dan fasilitas yang tersedia, misalnya sarana dan prasarana yang ada di Sky Rink, kemudian diolah berdasarkan teori yang ada, dengan studi kepustakaan dan jurnal-jurnal yang berkaitan dengan masalah yang dikaji serta digunakan sebagai landasan teori. 
Kemudian data tersebut diolah dengan menggunakan pendekatan SWOT (Strengths, Weaknesses, Opportunities, Threats) yang merupakan pengenalan kekuatan, kelemahan, peluang, dan ancaman dapat diperoleh dari banyak sumber, termasuk infomasi dari pengunjung, pemilik, ataupun dengan informasi yang ada.

$$
\text { Sugiono dalam (Nisak, 2013) }
$$
menyebutkan beberapa variable SWOT guna untuk menggambarkan peluang maupun kelemahan yang ada di sky rink Mall Taman Anggrek sehingga menghasilkan beberapa faktor yang dimiliki oleh sky rink yang dimaksud dalam gambar berikut ini:

\begin{tabular}{|c|c|c|}
\hline Eksternal & $\begin{array}{c}\text { (Internal) } \\
\text { Kekuatan/Strength (S) } \\
\text { Faktor-faktor } \\
\text { Kekuatan Internal }\end{array}$ & $\begin{array}{c}\text { (Internal) } \\
\text { Kelemahan/Weaknesses }(\boldsymbol{W}) \\
\text { Faktor-faktor Kelemahan } \\
\text { Internal }\end{array}$ \\
\hline $\begin{array}{c}\text { (Eksternal) } \\
\text { Peluang/Opportu } \\
\text { nities }(\boldsymbol{O})\end{array}$ & \begin{tabular}{l}
\multicolumn{1}{c}{ Strategi $\boldsymbol{S O}$} \\
$\mathbf{1}$ \\
Ciptakan strategi yang \\
menggunakan \\
kekuatan untuk \\
memanfaatkan \\
peluang
\end{tabular} & \begin{tabular}{l}
\multicolumn{1}{c}{ Strategi $\boldsymbol{W O}$} \\
$\mathbf{3}$ \\
Ciptakan strategi yang \\
meminimalkan kelemahan untuk \\
memanfaatkan peluang
\end{tabular} \\
\hline $\begin{array}{c}\text { (Eksternal) } \\
\text { Ancaman/Threat } \\
s(T)\end{array}$ & \begin{tabular}{l}
\multicolumn{1}{c}{ Strategi $\boldsymbol{S T}$} \\
$\mathbf{2}$ \\
Ciptakan strategi yang \\
menggunakan \\
kekuatan untuk \\
mengatasi ancaman
\end{tabular} & \begin{tabular}{l}
\multicolumn{1}{c}{ Strategi $\boldsymbol{W T}$} \\
$\mathbf{4}$ \\
Ciptakan strategi yang \\
meminimalkan kelemahan dan \\
menghindari ancaman
\end{tabular} \\
\hline
\end{tabular}

Diagram 1: Matriks SWOT.

(Sumber:(Rangkuti, 2002)

\section{PEMBAHASAN}

Di Indonesia Sky Rink adalah satu satunya tempat bermain seluncur es terluas, dengan luas $1.248 \mathrm{~m} 2$ yang terletak didalam Mall Taman Anggrek yang merupakan wahana gelanggan es terluas yang ada di Indonesia. Terletak di J1. Letjen S.Parman Kav.21 Lt.3 Jakarta - Barat. Sky Rink dibuka pada bulan agustus tahun 1996 dan kemuudian diresmikan PT. Sanggar Mustika Padma.

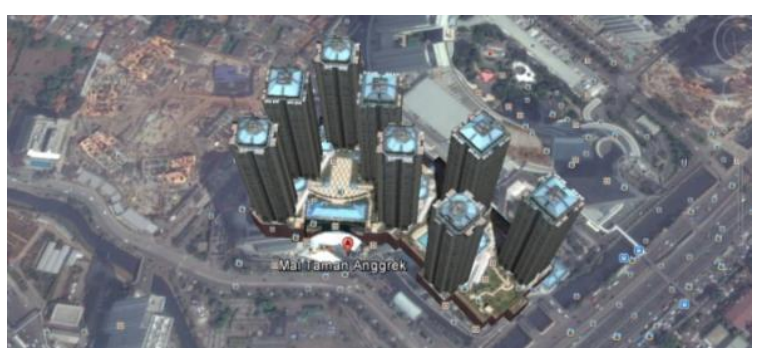

Gambar 1: lokasi sky rink di mall taman anggrek (Sumber: google maps, 2019)

Batasan Ice Skating "Ice Rink" Mall Taman Anggrek : (a) Batas Utara dengan Pemukiman Warga, (b) Batas Selatan dengan Pemukiman warga, (c) Batas Barat dengan Central Park (d) Batas Timur: Apartemen Taman Anggrek

Hasil Sky Rink dilengkapi dengan berbagai fasilitas pendukung diantaranya adalah peminjaman sepatu gratis untuk bermain ice skating, locker untuk menyimpan barang bawaan skater, snack bar, skating school (sekolah seluncur es yang bernaung dibawah ISI - Ice Skating Institute). Sky rink mengadakan kelas khusus untuk peminatan pada bidang Figure Skating dan Hockey Skating.

Sky Rink Jakarta telah mengadakan pertandingan baik lokal maupun internasional serta mengundang figure skate terbaik nasional hingga internasional. Sky rink juga menyediakan Pro Shop Sky Rink tempat menjual berbagai macam peralatan Ice Skating juga aksesoris Ice Skating. Fasilitas ruangan di sky rink menyediakan peminjaman sepatu, locker, snack bar, skating school, dan pro shop.

Sky Rink selalu ramai terutama pada hari sabtu-minggu dan hari libur. Agar tetap diminati oleh pelanggannya, Sky Rink selalu memberikan sesuatu yang dapat membuat para pelanggannya merasa puas. Salah satu bentuknya adalah dengan memberikan layanan bermain sepuasnya di setiap hari kerja, peminjaman sepatu skating gratis, layanan program diskon pada hari- 
hari tertentu (Great Monday, Bonanza Day, Karyawan Day, dan Campus Day), mengadakan event berupa pertunjukkan dan pertandingan es baik lokal maupun internasional.Pada umumnya jurnal internasional

Tabel 1: Harga tiket masuk sky rink

\begin{tabular}{|l|l|}
\hline Hari & Harga (Rp.) \\
\hline $\begin{array}{l}\text { Hari biasa (Senin- } \\
\text { Jumat) }\end{array}$ & Rp 65.000 (all day) \\
\hline $\begin{array}{l}\text { Hari sabtu / } \\
\text { minggu }\end{array}$ & Rp 80.000 (2 jam) \\
\hline
\end{tabular}

sumber: brosur sky rink

Terkait dengan preferensi pengunjung mall taman anggrek Jakarta, kebanyakan dari mereka hanya ingin berwisata atau mencoba wisata ice skating ini. Taman Anggrek ini sudah berdiri cukup lama dan mempunyai salah satu wahana yang tidak dimiliki mall lainnya yaitu ice skating, sehingga mindset masyarakat mengenai wisata ini sudah ada sejak mall tersebut berdiri.

Pada hari biasa, jumlah pengunjung ice skating sekitar 200-400 orang. Mayoritas dari pengunjung ice skating tersebut yaitu anak kecil maupun remaja yang masih menginjak bangu sekolah. Jumlah pengunjung akan terus meningkat pesat pada akhir pekan, dengan sekitar 1000 orang pengunjung. Serta sky rink menyediakan sekolah ice skating. Siswa bisa memilih, mau didampingi secara personal atau dalam grup. Hingga kini, Sky Rink telah mengajar belasan ribu siswa. Namun yang aktif saat ini mencapai 500 orang.

Berikut adalah perbedaan jumlah pengunjung Sky Rink Jakarta per harinya, baik hari biasa (senin-jumat), sabtu, minggu serta hari libur nasional:
Tabel 2: Jumlah Pengunjung Sky Rink

\begin{tabular}{|l|l|l|}
\hline No & Hari & $\begin{array}{l}\text { Jumlah } \\
\text { Pengunjung }\end{array}$ \\
\hline 1 & Senin - Jumat & $150-300$ Skaters \\
\hline 2 & Sabtu dan Minggu & $500-700$ Skaters \\
\hline 3 & Hari Libur & $>1000$ Skaters \\
\hline \multicolumn{2}{|l}{ Sumber: Data Info dari pihak Sky }
\end{tabular}

Rink, 2019

Tabel 3: Jumlah usia pengunjung Sky Rink (diambil dari 30 jumlah pengunjung)

\begin{tabular}{|l|l|l|}
\hline No & Hari & $\begin{array}{l}\text { Jumlah } \\
\text { Pengunjung }\end{array}$ \\
\hline 1 & $3-12$ Tahun & 2 \\
\hline 2 & $13-17$ Tahun & 15 \\
\hline 3 & $18-25$ Tahun & 6 \\
\hline 4 & $>25$ Tahun & 7 \\
\hline & Total & 30 Pengunjung \\
\hline
\end{tabular}

Sumber: Data Suvey, 2019

Berdasarkan hasil pada tabel diatas dapat disimpulkan bahwa pengunjung yang datang ke Sky Rink lebih banyak remaja berumur 11 hingga 17 tahun. Hal tersebut dikarenakan remaja-remaja ingin mencoba wahana baru, serta pikiran mereka dikarenakan jarang sekali ada tempat yang menghadirkan wahana sebagai tempat ice skating.

Potensi fisik yang dimiliki sky rink Mall Taman Anggrek adalah adalah segala sesuatu yang memiliki daya tarik pengunjung mall untuk datang ke tempat tersebut, adapun potensi fisik yang dimiliki yaitu:

Fasilitas Ice Rink, Ice Skating di Sky Rink merupakan terbesar di asia tenggara dengan luas $1,248 \mathrm{~m} 2$, dengan fasilitas utama yang disediakan oleh pihak pengelola Mall Taman Anggrek Jakarta untuk menambah daya tarik pengunjung mall. selain untuk tempat wisata, dan latihan, digunakan juga sebagai kejuaraan, pertunjukan figure skating, dan sekolah skating. 


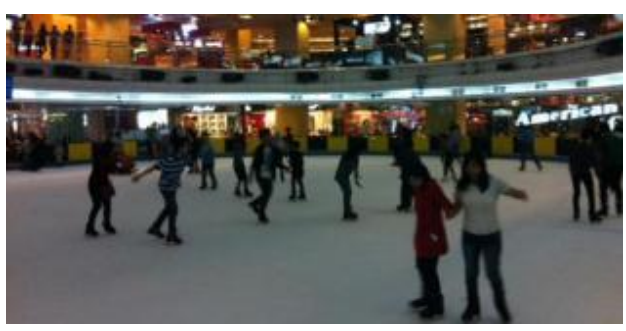

Gambar 2: Ice Skating Sky Rink Mall Taman Anggrek

Sumber : Data Survey, 2019

Fasilitas Snack Bar dan Ruang Tunggu, Merupakan fasilitas ruang khusus berjualan makanan dan minuman di Sky Rink Jakarta. Dengan luas ruangan $6 \mathrm{~m} \mathrm{x}$ $9 \mathrm{~m}$. pengunjung sekaligus pengantar ke sky rink bisa duduk sambil menunggu waktu bermain atau menunggu keluarga yang sedang bermain.

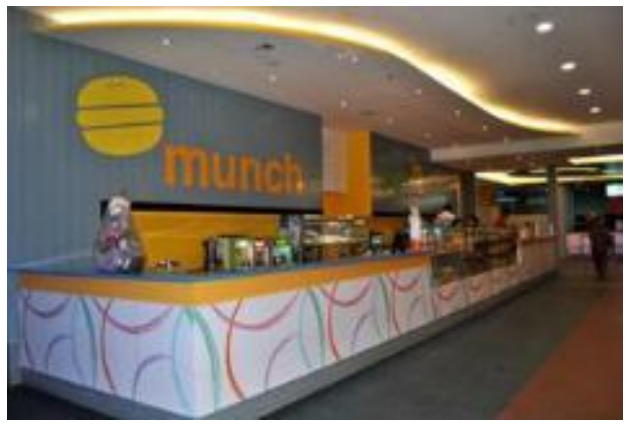

Gambar 3: Snack Bar \& Dapur

Sumber : Data Survey, 2019

Fasilitas Music/DJ Booth, Walaupun bukan sebagai fasilitas utama tetapi Sky Rink Jakarta menggunakan music booth dengan tujuan agar pengunjung tetap rileks dan bersemangat ketika bermain ice skating, dengan luas ruangan $3 \mathrm{~m} \times 7 \mathrm{~m}$.

Secara Potensi Non Fisik, Sebagai salah satu daya tarik yang menjadi faktor meningkatnya pengunjung mall yaitu potensi dalam pariwisata olahraga itu sendiri, karena pengunjung bisa ikut terlibat dan dapat berpartisipasi dalam olahraga ice skating ini, sehingga potensi olahraga ini menjadi kunci utama dalam potensi pariwisata ini. Karena pengunjung menjadi penasaran dan ingin mengetahui tentang olahraga musim dingin. Kegiatan tersebut bisa berupa event ataupun penawaran diskon, adapun kegiatan / acara yang bisa menarik pengunjung mall yaitu:

Festival Disney on Ice yang diselenggarakan tahun lalu, hingga pengunjung luar kota memesan tiket tersebut jauh hari sebelum hari penampilan, juga pihak Sky Rink mengadakan pertandingan baik lokal maupun internasional serta mengundang figure skate terbaik nasional hingga internasional.

Pertandingan kompetisi yang menarik pengunjung wisata misalnya event yang diselenggarakan Open International Figure Skating event di Sky Rink oleh ISI Asia dalam pertandingan figure skating yang menampilkan atraksi figure skaters dari belahan asia.

Selain menyediakan wahana ice skating, pihak Sky Rink Jakarta sering mengadakan strategi untuk menarik pengunjung lebih banyak. Yaitu Layanan diskon yang disediakan pada hari-hari tertentu (Great Monday, Bonanza Day, Karyawan Day, dan Campus Day). Serta pelayanan keramahan dari para coach / pelatih dalam melakukan pelayanan. Fasilitas Dj Booth dan music station yang ada di Sky Rink dengan tujuan agar pengunjung tetap rileks dan bersemangat ketika bermain ice skating.

Tingkat Aksesibilitas, mengenai aksesibilitas biasanya para pengunjung mall dapat langsung menemui lokasi tersebut. Karena merupakan salah satu destinasi wisata mall Taman Anggrek tidak banyak pengunjung mengunjungi mall karena ingin mengunjungi wisata olahraga ini. Oleh sebab itu banyak mall yang menjual wisata olahraga ice skating sebagai keunggulan untuk menarik pengunjung datang. Bangunan gelanggang es belum ada di 
Indonesia, sehingga fasilitas tersebut hanya terdapat di bagian mall.

Berdasarkan analisis SWOT (Strengths, Weaknesses, Opportunities, Threats) maka dapat diketahui beberapa startegi yang bisa diterapkan dalam pengembangan potensi wisata ice skating di dalam mall. Fenomena tersebut menimbulkan peluang bagi mall yang lainnya untuk mengembangkan konsep wisata olahraga untuk menarik pengunjung mall. Hal tersebut menimbulkan peluang dan ancaman eksternal untuk dihadapi kedepannya, sebagai wisata olahraga yaitu:

1. Kekuatan (Strengths)

Strategi ini merupakan cara untuk menonjolkan potensi-potensi kemungkinan yang bisa mendukung, menambah strategi misalnya menawarkan fasilitas selain olahraga tersebut, misalnya adanya coach (pelatih), alat-alat berskating, tutorial belajar, tersedianya music dan DJ Booth, dan lainnya yang menunjang dalam pengembangan wisata olahraga. Selain itu kelompok olahraga ini masih terbilang jarang untuk ditemui, sehingga persaingan dalam usaha ini masih terbilang longgar, rasa penasaran pengunjung untuk mencoba olahraga ini menjadi alasan untuk mencoba sekaligus sebagai sarana rekreasi bagi keluarga. Sehingga pengunjung dapat memiliki kesan yang baik mengenai wisata olahraga ini. Hal tersebut sesuai dengan (Soekadijo, 2000), bahwa ada beberapa kriteria untuk memenuhi sebagai atraksi wisata yang baik: (1) penyajian melalui sasaran yang tepat kepada wisatawan, sehingga wisatawan yang berkunjung merasa puas dan ingin kembali lagi. Kepuasan tersebut tidak dari atraksi wisata sendiri, tetapi bagaimana ia menampilkan dan mempresentasikan kepada wartawan / media. (2) meninggalkan kesan yang baik, para pengunjung datang untuk menikmati objek / lokasi yang memungkinkan meninggalkan kesan yang baik.

2. Kelemahan (Weakness)

Wisata olahraga ini memiliki kekurangan karena pemasangan dan biaya perawatan yang diperlukan, karena perawatan ice rink (lantai es) dan selalu menyediakan zamboni (mobil meratakan es) dilakukan untuk meratakan gundukan es yang terdapat pada permukaan ice rink. Gundukan tersebut terbentuk disebabkan oleh gesekan pisau pada sepatu ice skating yang membelah lapisan es.

Selain itu keperluan listrik ekstra untuk membeli mesin chiller untuk menjaga lapisan ice rink tetap dingin. Pengeluaran untuk mesin chiller bisa mencapai $45 \%$ dari pengeluaran untuk hal lainnya, dikarenakan mesin chiller harus tetap aktif sepanjang hari. Menurut pengurus dari Sky Rink mengatakan pembangunan ice rink harus memenuhi standar internasional. Perusahaan Sky Rink bekerja sama dengan perusahaan eropa yang sudah paham dalam mendirikan area ice skating. Untuk membuat arena ice skating membutuhkan dua hari / tiga hari, sebelum es dibekukan, lantai alas harus dilapisi dengan bahan-bahan khusus untuk menghindari kebocoran. Durasi dalam pelapisan es juga harus tetap sekitar 15-20 menit, oleh sebab itu arena harus dikosongkan terlebih dahulu, selain itu permukaan es yang tidak rata menyulitkan pengguna dalam berseluncur. Selain itu wisata jenis ini jarang di Indonesia dan hanya beberapa mall yang menggunakan wisata 
olahraga, sehingga perlu dikaji dan dipelajari untuk meminimaliskan kekurangan yang ada.

3. Peluang (Opportunities)

Potensi wisata ice sakting ini dapat membantu untuk mencpitakan lapangan kerja baru, misalnya kesempatan untuk menjadi coach (pelatih ice skating) untuk memperkenalkan pengunjung mengenai olahraga musim dingin ini. Dengan cara melatih untuk menjadi seorang coach, selain keterampilan yang dibutuhkan, kemampuan mengajar seseorang juga dibutuhkan, karena seseorang tidak semua langsung bisa menguasainya. Oleh sebab itu kesempatan untuk membuka sekolah ice skating juga menjadi sebuah kesempatan, selain untuk mengajarkan hal mengenai ice skating, hal tersebut menciptakan peluang usaha lainnya sebagai tambahan.

4. Ancaman (Threads)

Dalam mengembangkan wisata ice skating ini, hal-hal yang dapat menjadi ancaman bisa dapat terjadi, misalnya jika penanganan / manajemen tidak baik / tidak sesuai dengan standar yang ada, kemungkinan bisa menjadi sebuah ancaman yang serius baik dalam segi ekonomi, keselamatan pengunjung, maupun lingkungan. Oleh sebab itu perlu dikaji dalam mengelola ice skating ini. Selain itu penyediaan sarana dan prasarana yang baik untuk menunjang arena wisata olahraga ini agar lebih baik. Sehingga tidak menggangu perusahaan / proyek itu sendiri.

\section{SIMPULAN}

Tujuan pada penelitian ini yaitu mengetahui potensi - potensi ice skating terhadap minatnya warga kota Jakarta, salah satunya Sky Rink yang ada di Mall Taman Anggrek. Hingga kini wisata ice skating masih menjadi salah satu wisata favorit di Kota Jakarta. Pandangan masyarakat terhadap wisata yang hanya ditemuin di negara musim dingin menjadi salah satu faktor tingginya peminat masyarakat. Minatnya masyarakat dengan hadirnya fenomena wisata ice skating di dalam mall. Hal ini menyebabkan kehadiran mall-mall sekitar Kota Besar yang menerapkan wisata ice skating dalam mall, seperti BX Rink Bintaro XChange, dan yang baru saja dibangun Ice Skating Olympic Size, Mall Aeon. Dengan adanya wisata wisata ice skating, minat masyarakat menjadi tinggi sehingga terciptanya para atlet dalam bidang olahraga musim dingin, seperti figure skating / hockey.

\section{DAFTAR PUSTAKA}

Aulia Novita, J. R, Hubungan Kualitas Layanan Prima Humas Pt.Sanggar Mustika Padma (Sky Rink) Mall Taman Anggrek Jakarta Dengan Kepuasan Pelanggan Dalam Bermain Ice Skating, 2010.

P. De Knop, Sport tourism: A state of the art. European Journal of Sport Management, 1999, 5(2),pp 5-20.

H. Kodhyat, Pengertian Pariwisata dan Kepariwisataan. Yogyakarta, 1983.

E. Lion, Shopping centers: planning development, and administration. John Wiley \& Sons, . 1976.

Z. Nisak, Analisis SWOT untuk menentukan strategi kompetitif. Jurnal Ekbis, 2013, 9(2),pp 468-476.

M Nurhayati, Profitabilitas, likuiditas dan ukuran perusahaan pengaruhnya terhadap kebijakan dividen dan nilai perusahaan sektor non jasa. Jurnal Keuangan \& Bisnis Program Studi Magister Manajemen Sekolah Tinggi Ilmu Ekonomi Harapan,, 2013, 5(2), pp 144-153.

B. G. Pitts, Sports tourism and niche markets: Identification and analysis of the growing lesbian and gay sports tourism 
industry. Journal of Vacation Marketing, 1999, 5(1), pp 31-50.

F. Rangkuti, The power of brands. Gramedia Pustaka Utama, 2002.

$\mathrm{R}$ Rubenstein, The cunning of history. HarperCollins Publishers, 1978.

W. K Sari, Peran Department Marketing Communication Dalam Mendukung Penyelenggaraan Event Di The Park Mall Solo Baru. Universitas Sebelas Maret, 2017.

R. G Soekadijo, Anatomi pariwisata: memahami pariwisata sebagai" systemic linkage. Gramedia Pustaka Utama, 2000.
A. P Wardana, \& Sanawiri, B. Potensi Sport Tourism Sebagai Daya Tarik Wisata Di Malang Raya (Studi kasus pada klub sepakbola Arema FC ), 2018, 55(1), pp 180-187.

O. A Yoeti, Perencanaan \& pengembangan pariwisata. Jakarta: PT Pradnya Paramita, 2008. 